CARDIOVASCULAR MEDICINE

\title{
Temperature at birth, coronary heart disease, and insulin resistance: cross sectional analyses of the British women's heart and health study
}

\author{
D A Lawlor, G Davey Smith, R Mitchell, S Ebrahim
}

Heart 2004;90:381-388. doi: 10.1136/hrt.2002.009548

See end of article for authors' affiliations

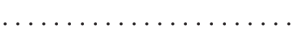

Correspondence to: Dr D A Lawlor, Department of Social Medicine, University of Bristol, Canynge Hall, Whiteladies Road, Bristol BS8 2PR, UK: d.a.lawlor@bristol.ac.uk

Accepted

2 September 2003

\begin{abstract}
Objective: To assess the association of mean outdoor temperature around the time of birth with insulin resistance and coronary heart disease in later life.

Design: Cross sectional study.

Setting: 23 British towns.

Participants: 4286 women aged 60-79 years.

Main outcome measures: Coronary heart disease and insulin resistance.

Results: Coronary heart disease prevalence was greatest among women born during the coldest months: the age adjusted odds ratio comparing women born in the coldest quarter of monthly outdoor birth temperatures with the remaining three quarters was 1.24 (95\% confidence interval (CI) 1.03 to 1.50$)$. Cold outdoor temperature at birth was also associated with increased insulin resistance, increased triglyceride concentrations, and poorer lung function. The link between cold outdoor temperature at birth and coronary heart disease was only partly explained by known coronary disease risk factors: fully adjusted (for all measured potential explanatory and confounding factors) odds ratio 1.19 (95\% $\mathrm{Cl} 0.95$ to 1.48 ). The association between cold temperature at birth and coronary heart disease was most pronounced among those whose fathers were either unemployed or in manual social classes when the participants were children, and was non-existent in those from non-manual social classes in childhood.

Conclusions: Cold outdoor temperature at birth is associated with increased coronary heart disease, insulin resistance, dyslipidaemia, and poor lung function. Further research is needed to determine whether this finding reflects events occurring late in the third trimester of intrauterine growth or early in the postnatal period.
\end{abstract}

$\mathrm{T}$ he idea that season of birth is related to disease and other adverse outcomes in later life has been postulated for at least six decades, since Ellsworth Huntington wrote his thesis Season of birth: its relation to human abilities. ${ }^{1}$ With contemporary interest in the early life origins of adult diseases some investigators have revisited this area of research. ${ }^{23}$

Various population studies have found life expectancy or mortality to be affected by season of birth. ${ }^{1-6}$ In the largest of these studies, the association between life expectancy at age 50 years and month of birth was assessed for two northern hemisphere countries (Austria and Denmark) and one southern hemisphere country (Australia). ${ }^{2}$ It was found that in Austria and Denmark life expectancy was longest for those born in October to December, and in Australia this pattern was, as expected, shifted by six months. ${ }^{2}$ For the Austrian data only, cause specific mortality was examined and mortality from both coronary heart disease and stroke was found to be greatest among those born between April and June and least among those born between October and December. These associations were not explained by seasonal distributions of death, selective survival in the first year of life, or socioeconomic factors. The investigators concluded that intrauterine or early infancy effects explained the association. Specifically, as a cohort effect was noted-with much weaker effects in contemporary compared with older birth cohorts-they suggested that seasonal food scarcity during intrauterine development explained seasonal patterning of life expectancy in the older cohorts. ${ }^{2}$

Results from a recent Ukraine study are consistent with those from Austria and Denmark, ${ }^{3}$ supporting intrauterine nutritional programming as the most likely explanation because of the known effects of seasonal climatic changes on food availability in the Ukraine over the time period of the study. ${ }^{3}$ However, this hypothesis is not supported by data from rural Gambia, where seasonal food scarcity is more acute; the data showed no difference in insulin resistance, components of the insulin resistance syndrome, or anthropometric measures between those born during the "hungry" season and those born during the "harvest" season. ${ }^{7}$

An alternative explanation for the associations between season of birth and all-cause or coronary heart disease mortality is a direct effect of temperature on adipocyte development, obesity, insulin resistance, and thence disease outcomes. $^{8-10}$ Animals exposed to lower environmental temperatures at birth store more dietary energy as fat even after the period of exposure to cold temperatures. ${ }^{10}$ Human studies also suggest that those who are born during cold seasons tend to be more obese in later life. ${ }^{911-13}$ Most of these studies have been conducted on young male army recruits and may not be generalisable to older men or to women. However, a recent study of older British women and men found that, in men only, being born during colder months was associated with a higher mean body mass index and a greater prevalence of obesity. ${ }^{13}$

One way to examine whether exposure to cold outdoor temperatures has a more important effect than nutritional deprivation would be to assess the association between temperature around the time of birth as opposed to the season of birth. Our aim in this study was to assess the associations of mean outdoor temperature around the time of 
birth with insulin resistance and coronary heart disease in a cohort of postmenopausal women.

\section{METHODS}

\section{Participants}

The British women's heart and health study is a sample of women aged 60-79 years randomly selected from general practitioner lists in 23 British towns. In all, 4286 women ( $60 \%$ of those invited) participated, and baseline data (self completed questionnaire, research nurse interview, physical examination, and primary care medical record review) were collected between April 1999 and March 2001. Ethics committee approval was obtained and full details of the study have been published. ${ }^{14}$

\section{Assessment of temperature at birth and during fetal development}

Dates of birth for each participant were initially obtained from their general practice medical records and were confirmed at research nurse interview. Each participant was asked their town or city of birth and also whether this was in the same county or country of their current residence. Monthly outdoor air temperature data for each month, year, and place of birth for each participant were obtained from the Climatic Research Unit at the University of East Anglia. ${ }^{15}$ These data consist of an observation based model providing mean temperature for every month from January 1901 to December 1998. The dataset covers the whole globe but is at a spatial resolution of $0.5^{\circ}$ (longitude/latitude) units, which divides the land mass of the British Isles into approximately 300 grid cells of around $20 \times 35$ miles each. The gridded model was interpolated from the most comprehensive set of weather station observation records, and forms the finest scaled, most reliable, and most temporally complete climate record available. ${ }^{15}$ We wrote software to extract records for the grid cells which comprise the British Isles from the global set. Figure 1 shows an example of the outdoor temperature data for 1914 for the British Isles.

We matched each study participant to these data by matching their place of birth to the appropriate grid cell in the climate dataset using a geographical information system. ${ }^{16}$ Contemporary settlement boundaries were used to match birth place to grid cell, on the assumption that the physical extent of a district identified by a particular name remains broadly similar to that in the period in which these women were born (1919 to 1940). Where a contemporary definition of a town or city overlapped by more than one grid cell, the cell which had the greatest intersection with the area enclosed by the town or city boundary was selected. For

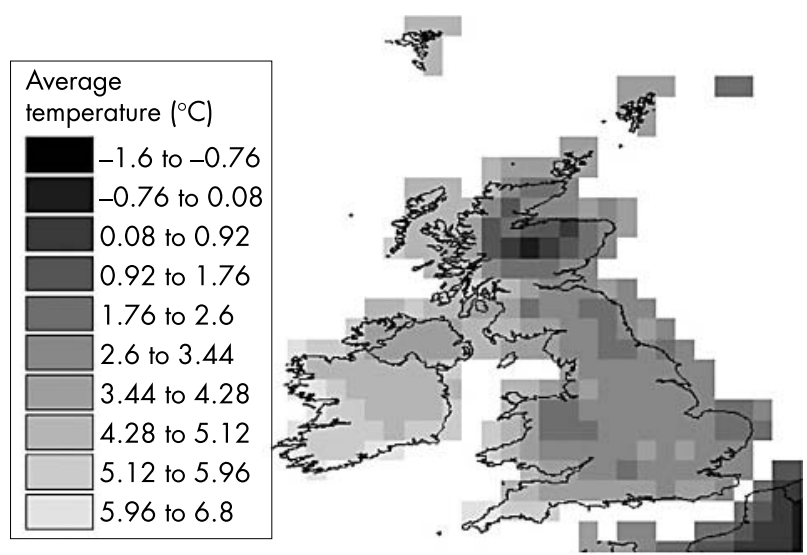

Figure 1 Grid based climate data for the British Isles (average temperature for January 1914). mean ambient temperature around the time of birth we then extracted the climate record for each participant's month and year of birth. We estimated the approximate midpoint of the first, mid, and last trimesters of intrauterine development for each participant as their date of birth minus 32, 20, and eight weeks, respectively, and then calculated mean temperatures for these times in the same way as for time of birth.

In addition to assessing the associations with mean monthly temperature around the time of birth we assessed the associations of coronary heart disease and risk factors with season and month of birth. This was done so that we could assess whether the previously reported associations were indeed related to temperature exposure as opposed to other factors related to season such as food availability, ${ }^{23}$ daylight exposure, ${ }^{17}$ or exposure to certain seasonal infections. ${ }^{18}$ Seasons were defined using the usual British dates of the March equinox, summer solstice, September equinox, and winter solstice: autumn (September 23 to December 21), winter (December 22 to March 20), spring (March 21 to June 20 ), and summer (June 21 to September 22). Each participant was allocated to a season of birth based on their date of birth.

Assessment of coronary heart disease and risk factors Prevalent coronary heart disease was defined as any participant with a primary care record of myocardial infarction or angina, or anyone who reported ever being diagnosed by a doctor with one of these conditions. ${ }^{14}$ Details of measurements of insulin resistance risk factors, childhood and adult social class, and adult anthropometric measures have been reported previously. ${ }^{14} 1920$ Women were asked to report their birth weight in the self completed questionnaire.

\section{Statistical analysis}

To illustrate the shape and directions of associations between temperature around the time of birth and coronary heart disease and other characteristics, quarters of temperature were used. Multiple linear regression and multiple logistic regression were used to estimate age adjusted prevalences and the means of coronary heart disease and coronary heart disease risk factors across quarters of birth temperature. In these models, quarters of temperature were entered as indicator variables and age was centred around the mean of the cohort. Multiple regression was used to assess linear trends across these quarters, with temperature quarters entered as a numerical variable; departure from a linear trend was assessed by a likelihood ratio test. Multiple logistic regression was used to assess the association between being in the coldest quarter of birth temperatures (compared with the warmest three quarters) and coronary heart disease prevalence, with adjustment for potential confounding or intermediary factors.

A series of regression models was developed to determine the effects of potential confounding or mediating factors on the associations. Each model was compared with the age adjusted association.

In the first model the hypothesis that insulin resistance might mediate the association between temperature around the time of birth and adult heart disease was assessed by adjustment for insulin resistance diabetes, triglyceride values, high density lipoprotein cholesterol, systolic and diastolic blood pressure, and waist-hip ratio. If insulin resistance and its associated metabolic risk factors were important mediators, then one would expect the age adjusted association to attenuate with additional adjustment for these risk factors.

In the second model the possibility that the association was mediated through early life factors that affected lung development was assessed by adjustment for forced expiratory volume in one second $\left(\mathrm{FEV}_{1}\right)$; in this model smoking 
was also included, as this is an important determinant of both lung function and coronary heart disease.

In the third model the effects of adjustment for anthropometric measures (leg length, trunk length, and body mass index) were assessed.

The possibility that the association was explained by social class across the life course, season or month of birth, or simply reflected the known association between latitude and coronary heart disease risk, was assessed by separate models including childhood and adult social class, together with years of completed full time education, season of birth, month of birth, and latitude. In these models age, body mass index, waist-hip ratio, systolic and diastolic blood pressure, high density lipoprotein cholesterol, triglyceride values, and years of education were all entered as continuous variables. Because homeostasis model assessment of insulin resistance (HOMA) scores were not estimated on participants with diabetes, in order to be able to enter complete data on the spectrum of insulin resistance diabetes we generated a six category variable in which the first five categories were fifths of HOMA score and the sixth category was diabetes. We entered this along with smoking (never, ex, current), season of birth, and month of birth as indicator variables so that no assumptions were made about the shape of their associations with the main exposure and outcome of interest.

Of the 4286 women, 425 could not be assigned an adult occupational social class and 545 could not be assigned a childhood occupational social class because they did not provide data on occupation. Although the participants were not specifically asked about unemployment, these women are likely to have been married to unemployed men (for those with missing adult data) and had fathers who were unemployed (for those with missing childhood data). This is consistent with the findings that women without these data on social class were a relatively homogeneous group and were more likely to smoke, to be obese, to be shorter, and to have prevalent coronary heart disease than all cohort members who provided these data, but had similar distributions of these factors to women in the lowest social class (V) at either stage in their life course. ${ }^{20}$

In the main analysis childhood and adult social class were entered into the models as indicator variables (for the six occupational groups), with a seventh indicator variable representing women with missing data. A sensitivity analysis was conducted in which women with these missing data were excluded from the analysis. These results did not differ substantially from the main analyses and have not been presented in this paper.

Mean outdoor temperature around the time of birth does not necessarily indicate that a particular individual was exposed to cold, because of individual variation with respect to access to a well heated home and warm clothing. To assess such an effect on individuals, we stratified the analyses by childhood socioeconomic position. This was done by examining the association in three groups: those whose fathers' longest held occupation during their childhood was manual (manual childhood social class), those whose fathers were in a non-manual occupation (non-manual childhood social class), and those who did not provide occupational data for their fathers (most probably long term unemployed fathers, see above).

HOMA scores and triglyceride concentrations had positively skewed distributions but logged values were normally distributed; geometric means are presented, and logged values were used in the regression models. With these transformations, residuals were normally distributed in all models. In all analyses robust confidence intervals were estimated, which take into account the clustering between participants from the same towns.

\section{RESULTS}

Compared with non-responders, women who participated in the study were younger (mean (SD) age of participants, 68.8 (5.5) years $v 70.2(5.9)$ years for non-responders, $\mathrm{p}<0.001$ ), but there was no difference in the prevalence of general practitioner recorded coronary heart disease between participants and non-responders (prevalence (95\% confidence interval (CI)) of myocardial infarction for participants, 3.2\% (2.7\% to $3.8 \%)$ and for non-responders, $3.3 \%$ (2.7\% to $4.1 \%)$, $\mathrm{p}=0.8$; results for angina were $11.0 \%$ ( $10.1 \%$ to $12.5 \%) v$ $10.1 \%(9.0 \%$ to $11.3 \%)$, respectively, $\mathrm{p}=0.2)$. The prevalence of general practitioner recorded diabetes was lower among participants than among non-responders $(4.8 \%(4.2 \%$ to $5.5 \%) v 7.1 \%(6.7 \%$ to $8.8 \%), \mathrm{p}<0.001)$.

Of the 4286 participants, 694 had coronary heart disease, giving a prevalence of $16.2 \%$ ( $15.1 \%$ to $17.3 \%)$; $80 \%$ of these cases were identified in both the medical record review and by self report of a doctor diagnosis, $13 \%$ were in the record review only, and $7 \%$ self report only. We were able to allocate respondents to the grid cell appropriate to their place of birth for 4091 participants (95\%); of the remaining 5\% $(n=195)$, 148 were born outside of the British Isles (while we did have climate data for other countries, the recorded place of birth was too general (for example, Africa or France) to make a reliable match for these respondents. A further 47 did not provide details of their place of birth.

\section{Associations of temperature and season of birth with coronary heart disease}

Table 1 shows coronary heart disease prevalence and other characteristics across quarters of mean outdoor temperature for month of birth. Women who were born during the coldest months had a higher prevalence of coronary heart disease than those born in other months, were more likely to be insulin resistant, had higher triglyceride concentrations, and had a tendency to worse lung function as assessed by $\mathrm{FEV}_{1}$. The association between poorer lung function and temperature at birth was unaffected by further adjustment for smoking status. There was no evidence of strong associations between temperature around the time of birth and any anthropometric measures, though waist-hip ratio was thinnest among those born in the hottest periods. Social class in childhood or adulthood were not associated with temperature around the time of birth, but women who were born in the months with the coldest temperatures were likely to have left full time education at a slightly younger age.

Table 2 shows these same characteristics by season of birth. Women born in the winter had a higher prevalence of coronary heart disease and worse lung function. Women born in the spring tended to be most insulin resistant, but other metabolic risk factors were not associated with season of birth. Total height, and more specifically leg length, tended to be less among women born in the summer, but other anthropological measures were not associated with season of birth. Social class in childhood or adulthood were not related to season of birth, but women who were born in the winter and autumn tended to have left full time education at a slightly younger age than those who were born in the spring and summer. Figure 2A shows the higher age adjusted prevalence of coronary heart disease among those born in the months December through to March compared with other months.

Table 3 shows the odds ratios for coronary heart disease, comparing those born in the coldest quarter of mean monthly outdoor temperatures with the warmest three quarters. Those born in the coldest months had a $24 \%$ increased odds of coronary heart disease (age adjusted odds ratio $1.24,95 \%$ CI 1.03 to 1.50 ). This was partially explained by the association between temperature at birth and metabolic risk factors and 
Table 1 Age adjusted prevalence of coronary heart disease and age adjusted means and prevalences of coronary heart disease risk factors by quarters of mean monthly outdoor air temperature for month of birth

\begin{tabular}{|c|c|c|c|c|c|}
\hline & \multicolumn{4}{|c|}{ Average monthly outdoor temperature at birth quarters } & \multirow[b]{2}{*}{$\mathrm{p}$ Trend } \\
\hline & -2.0 to $5.4^{\circ} \mathrm{C}(\mathrm{n}=1031)$ & 5.5 to $8.9^{\circ} \mathrm{C}(n=1040)$ & 9.0 to $13.3^{\circ} \mathrm{C}(n=1005)$ & 13.4 to $19.7^{\circ} \mathrm{C}(n=1015)$ & \\
\hline $\mathrm{CHD}(\%)$ & $18.1(15.8$ to 20.6$)$ & $15.8(13.7$ to 18.2$)$ & $14.3(12.3$ to 16.6$)$ & $14.8(12.7$ to 17.1$)$ & 0.03 \\
\hline \multicolumn{6}{|l|}{ Metabolic risk factors } \\
\hline \multicolumn{6}{|l|}{ Systolic blood pressure } \\
\hline \multicolumn{6}{|l|}{ Diastolic blood pressure } \\
\hline$(\mathrm{mm} \mathrm{Hg})$ & 79.2 (78.5 to 80.0$)$ & $79.3(78.5$ to 80.0$)$ & 79.5 (78.8 to 80.3$)$ & 79.6 (78.9 to 80.4$)$ & 0.39 \\
\hline LDLC (mmol/l) & $4.07(4.00$ to 4.14$)$ & $4.19(4.11$ to 4.26$)$ & $4.22(4.14$ to 4.29$)$ & $4.11(4.04$ to 4.18$)$ & 0.36 \\
\hline $\mathrm{HDLC}(\mathrm{mmol} / \mathrm{l})$ & 1.65 (1.62 to 1.68$)$ & $1.65(1.62$ to 1.68$)$ & $1.66(1.63$ to 1.69$)$ & $1.65(1.62$ to 1.68$)$ & 0.81 \\
\hline \multicolumn{6}{|l|}{ Insulin resistance } \\
\hline 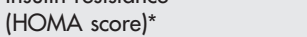 & $1.72(1.64$ to 1.79$)$ & $1.68(1.61$ to 1.76$)$ & $1.68(1.60$ to 1.76$)$ & 1.60 (1.53 to 1.67$)$ & 0.04 \\
\hline Diabetes (\%) & $7.1(5.6$ to 8.9$)$ & $7.4(5.9$ to 9.2$)$ & $7.0(5.5$ to 8.7$)$ & $6.7(5.5$ to 8.8$)$ & 0.68 \\
\hline \multicolumn{6}{|l|}{ Anthropometric measures } \\
\hline Birth weight $(\mathrm{kg})$ & $3.22(3.13$ to 3.30$)$ & $3.32(3.24$ to 3.40$)$ & 3.31 (3.24 to 3.40 ) & 3.34 (3.25 to 3.42$)$ & 0.07 \\
\hline Offspring birth weight $(\mathrm{kg})$ & 3.25 (3.22 to 3.29$)$ & 3.25 (3.22 to 3.29$)$ & 3.24 (3.20 to 3.28$)$ & 3.22 (3.18 to 3.26$)$ & 0.19 \\
\hline Weight (kg) & $69.6(68.8$ to 70.4$)$ & $69.6(68.8$ to 70.4$)$ & 69.5 (68.6 to 70.3$)$ & $69.3(68.5$ to 70.2$)$ & 0.61 \\
\hline BMI $\left(\mathrm{kg} / \mathrm{m}^{2}\right)$ & $27.7(27.3$ to 28.0$)$ & 27.5 (27.2 to 27.8$)$ & $27.6(27.3$ to 27.9$)$ & $27.6(27.2$ to 28.9$)$ & 0.68 \\
\hline Obese $\left(\mathrm{BMI}>30 \mathrm{~kg} / \mathrm{m}^{2}\right)(\%)$ & $27.7(25.0$ to 30.7$)$ & 26.1 (23.4 to 29.0$)$ & 24.9 (22.2 to 27.8$)$ & 27.1 (24.3 to 30.0$)$ & 0.62 \\
\hline Waist-hip ratio & $0.820(0.816$ to 0.825$)$ & $0.818(0.814$ to 0.822$)$ & $0.822(0.818$ to 0.826$)$ & $0.815(0.810$ to 0.819$)$ & 0.13 \\
\hline Height $(\mathrm{m})$ & 1.583 (1.580 to 1.588$)$ & $1.590(1.586$ to 1.594$)$ & 1.587 (1.582 to 1.591$)$ & 1.585 (1.580 to 1.589$)$ & 0.90 \\
\hline Leg length $(\mathrm{m})$ & $0.756(0.754$ to 0.759$)$ & $0.760(0.757$ to 0.762$)$ & $0.757(0.754$ to 0.759$)$ & $0.756(0.753$ to 0.759$)$ & 0.88 \\
\hline Trunk length $(\mathrm{m})$ & $0.830(0.828$ to 0.832$)$ & $0.831(0.829$ to 0.833$)$ & 0.830 (0.828 to 0.833$)$ & 0.831 (0.828 to 0.832$)$ & 0.91 \\
\hline \multicolumn{6}{|l|}{ Smoking and lung function } \\
\hline Ever smoked (\%) & 43.8 (40.9 to 46.7$)$ & 42.9 (39.8 to 46.0$)$ & 44.2 (41.2 to 47.3 ) & 46.9 (43.9 to 49.8 ) & 0.14 \\
\hline Current smoker (\%) & $11.2(9.5$ to 13.4$)$ & 11.5 (10.0 to 13.5$)$ & 12.2 (10.3 to 14.3$)$ & $10.6(8.8$ to 12.7$)$ & 0.78 \\
\hline $\mathrm{FEV}_{1}(\mathrm{I})$ & 1.95 (1.92 to 1.98$)$ & 1.98 (1.95 to 2.01$)$ & $1.96(1.93$ to 2.00$)$ & 2.00 (1.97 to 2.03$)$ & 0.10 \\
\hline \multicolumn{6}{|l|}{ Social class and education } \\
\hline \multicolumn{6}{|c|}{ Adult manual social class (\%) 52.4 (49.1 to 55.6 ) } \\
\hline Childhood manual social class & & & & & \\
\hline \multicolumn{6}{|l|}{$\begin{array}{l}(\%) \\
\text { Age at completion of full }\end{array}$} \\
\hline $\begin{array}{l}\text { Age at completion of full } \\
\text { time education (years) }\end{array}$ & 15.5 (15.3 to 15.8$)$ & $15.6(15.4$ to 15.8$)$ & 15.8 (15.4 to 15.8$)$ & $15.8(15.6$ to 16.1$)$ & 0.04 \\
\hline
\end{tabular}

Values are mean ( $95 \%$ confidence interval).

*Geometric mean.

BMI, body mass index; $\mathrm{CHD}$, coronary heart disease; $\mathrm{FEV}_{1}$, forced expiratory volume in one second; HDLC, high density lipoprotein cholesterol; HOMA,

homeostasis model assessment of insulin resistance; LDLC, low density lipoprotein cholesterol.

between temperature at birth and lung function, though some association remained even with adjustment for these factors and other potential mediating and confounding variables (fully adjusted odds ratio 1.19 , 95\% CI 0.95 to $1.48)$.

There was a strong association between mean monthly outdoor temperature at birth and season of birth, with the mean (SD) birth temperature for those born in the winter being $4.46(1.84)^{\circ} \mathrm{C}$, those born in the autumn $7.65(2.11)^{\circ} \mathrm{C}$, those born in the spring $9.73(2.97){ }^{\circ} \mathrm{C}$, and those born in the summer $14.72(1.87){ }^{\circ} \mathrm{C}(\mathrm{p}$ difference $<0.0001)$. The association between temperature at birth and coronary heart disease was not affected by adjustment for season of birth or month of birth (table 3). Being born in the winter was associated with a $39 \%$ increased odds of coronary heart disease prevalence (age adjusted odds ratio 1.39, 95\% CI 1.16 to 1.67). However, this association was completely attenuated by adjustment for mean outdoor temperature around the time of birth (age and temperature of birth adjusted odds ratio $1.00,95 \%$ CI 0.92 to 1.08 ). Figure 2 shows the age (panel A) and age plus temperature (panel B) adjusted prevalences of coronary heart disease by month of birth. In the age adjusted analyses, this prevalence is greater for the winter months (December to March); with additional adjustment for mean outdoor temperature for the month of birth this pattern disappeared.

Table 4 shows the associations between cold outdoor temperature around the time of birth and coronary heart disease, stratified by childhood socioeconomic class. The association between cold temperature around the time of birth was strongest for those without occupational data for their fathers (fathers most probably long term unemployed), intermediate for those whose fathers belonged to manual social classes, and weak (or non-existent in the fully adjusted model) for those whose fathers belonged to non-manual social classes.

Of the 4286 participants, 1394 (33\%) provided details of their birth weight. Those providing birth weight data were younger than those not providing these data (67.9 years $v 69.4$ years), but there was no substantial difference in age adjusted prevalence of coronary heart disease between these two groups (age adjusted odds ratio comparing those with data and those without $0.90,95 \%$ CI 0.74 to 1.07; $p=0.15)$. There was a positive association between temperature at birth and birth weight, with those born during the months of coldest outdoor temperatures having the lowest birth weight (table 1); those born in the winter were also likely to have lower birth weights than those born in other seasons (table 2). Within this subgroup of 1394 women, the age adjusted odds ratio for coronary heart disease comparing those born in the coldest quarter of birth temperatures with those in the warmest three quarters was 1.32 (95\% CI 0.94 to 1.90); with further adjustment for birth weight this was not substantially altered (1.30, 95\% CI 0.92 to 1.83 ).

\section{Associations of temperature during intrauterine development with coronary heart disease}

Temperature during the estimated first trimester of intrauterine development was not associated with coronary heart disease prevalence or with any of the coronary heart disease risk factors (all $\mathrm{p}$ values for trend $>0.2$ ). Cold exposure 
Table 2 Age adjusted prevalence of coronary heart disease and age adjusted means and prevalences of coronary heart disease risk factors by season of birth

\begin{tabular}{|c|c|c|c|c|c|}
\hline & $\begin{array}{l}\text { Summer June } 21 \\
\text { to Sept } 22(n=1120)\end{array}$ & $\begin{array}{l}\text { Autumn Sept } 23 \\
\text { to Dec } 21(n=1007)\end{array}$ & $\begin{array}{l}\text { Winter Dec } 22 \text { to } \\
\text { March } 20 \text { (n= 1042) }\end{array}$ & $\begin{array}{l}\text { Spring March } 21 \\
\text { to June } 20(n=1117)\end{array}$ & $\begin{array}{l}\text { Difference between } \\
\text { seasons of birth } \\
\text { ( } p \text { value) }\end{array}$ \\
\hline \multicolumn{6}{|l|}{$\begin{array}{l}\text { CHD (\%) } \\
\text { Metabolic risk factors }\end{array}$} \\
\hline $\begin{array}{l}\text { Metabolic risk factors } \\
\text { Systolic blood pressure }\end{array}$ & & & & & \\
\hline $\begin{array}{l}\text { (mm Hg) } \\
\text { Diastolic blood pressure }\end{array}$ & 147.6 (146.1 to 149.2$)$ & $147.4(145.8$ to 149.0$)$ & $147.4(145.8$ to 149.0$)$ & $146.1(144.6$ to 147.6$)$ & 0.51 \\
\hline (mm Hg) & 79.6 (78.9 to 80.4$)$ & 79.6 (78.9 to 80.4$)$ & 79.5 (78.8 to 80.3 ) & 78.9 (78.2 to 79.6$)$ & 0.47 \\
\hline LDLC (mmol/l) & $4.17(4.10$ to 4.24$)$ & $4.17(4.10$ to 4.24$)$ & $4.11(4.04$ to 4.18$)$ & $4.12(4.07$ to 4.19$)$ & 0.56 \\
\hline $\mathrm{HDLC}(\mathrm{mmol} / \mathrm{l})$ & $1.66(1.63$ to 1.68$)$ & $1.64(1.61$ to 1.66$)$ & 1.66 (1.63 to 1.69$)$ & $1.67(1.64$ to 1.70$)$ & 0.37 \\
\hline $\begin{array}{l}\text { Triglycerides }(\mathrm{mmol} / \mathrm{l})^{*} \\
\text { Insulin resistance }\end{array}$ & 1.65 (1.60 to 1.70$)$ & 1.68 (1.63 to 1.73 ) & 1.68 (1.63 to 1.73$)$ & 1.66 (1.62 to 1.72$)$ & 0.69 \\
\hline (HOMA score) $)^{*}$ & 1.65 (1.58 to 1.72 ) & 1.62 (1.54 to 1.68$)$ & $1.68(1.60$ to 1.75$)$ & 1.72 (1.65 to 1.79$)$ & 0.15 \\
\hline \multicolumn{6}{|l|}{ Anthropometric measures } \\
\hline Birth weight $(\mathrm{kg})$ & 3.29 (3.21 to 3.37 ) & 3.29 (3.21 to 3.38 ) & 3.21 (3.12 to 3.29 ) & 3.33 (3.25 to 3.41$)$ & 0.17 \\
\hline Offspring birth weight $(\mathrm{kg})$ & $3.22(3.18$ to 3.25$)$ & 3.24 (3.20 to 3.28$)$ & 3.26 (3.22 to 3.29$)$ & 3.25 (3.22 to 3.29$)$ & 0.42 \\
\hline Weight (kg) & $69.0(68.2$ to 69.8$)$ & 69.5 (68.7 to 70.3 ) & 69.5 (68.7 to 70.3$)$ & $70.3(69.5$ to 71.1$)$ & 0.62 \\
\hline \multicolumn{6}{|l|}{ Obese (BMI $>30 \mathrm{~kg} / \mathrm{m}^{2}$ ) } \\
\hline (\%) & $25.7(23.2$ to 28.5$)$ & $25.2(22.6$ to 28.1$)$ & $26.8(24.1$ to 29.7$)$ & 28.0 (25.4 to 30.9 ) & 0.48 \\
\hline Waist-hip ratio & $0.817(0.813$ to 0.821$)$ & $0.820(0.816$ to 0.825$)$ & $0.820(0.815$ to 0.824$)$ & $0.819(0.814$ to 0.823$)$ & 0.77 \\
\hline Height (m) & $1.582(1.579$ to 1.586$)$ & $1.590(1.586$ to 1.594$)$ & 1.587 (1.584 to 1.592$)$ & $1.586(1.582$ to 1.590$)$ & 0.10 \\
\hline Leg length $(\mathrm{m})$ & 0.755 (0.752 to 0.758$)$ & 0.759 (0.756 to 0.762$)$ & $0.759(0.756$ to 0.761$)$ & 0.757 (0.754 to 0.759$)$ & 0.07 \\
\hline Trunk length (m) & $0.829(0.827$ to 0.831$)$ & 0.832 (0.830 to 0.834$)$ & $0.829(0.826$ to 0.831$)$ & 0.832 (0.829 to 0.834$)$ & 0.15 \\
\hline \multicolumn{6}{|l|}{ Smoking and lung function } \\
\hline Ever smoked (\%) & 43.8 (40.9 to 46.7$)$ & $42.9(39.8$ to 46.0$)$ & $44.2(41.2$ to 47.3$)$ & $46.9(43.9$ to 49.8$)$ & 0.28 \\
\hline Current smoker (\%) & $11.4(9.7$ to 13.4$)$ & $11.3(9.5$ to 13.4$)$ & $10.9(9.2$ to 13.0$)$ & $12.8(10.9$ to 15.0$)$ & 0.55 \\
\hline & 1.97 (1.94 to 2.00$)$ & 1.99 (1.96 to 2.02 ) & 1.95 (1.92 to 1.98$)$ & $1.97(1.94$ to 2.00$)$ & 0.09 \\
\hline \multicolumn{6}{|l|}{ Social class and education } \\
\hline & $51.0(47.8$ to 54.1$)$ & 50.7 (47.4 to 54.0 ) & 51.8 (48.6 to 55.1 ) & 52.8 (50.0 to 55.9 ) & 0.80 \\
\hline \multicolumn{2}{|l|}{ Childhood manual social } & & & & \\
\hline \multicolumn{6}{|l|}{$\begin{array}{l}\text { class (\%) } \\
\text { Age at completion of full }\end{array}$} \\
\hline time education (years) & 15.9 (15.7 to 16.2 ) & 15.7 (15.5 to 16.0$)$ & 15.6 (15.3 to 15.8$)$ & $15.9(15.6$ to 16.1$)$ & 0.23 \\
\hline
\end{tabular}

Values are mean (95\% confidence interval).

${ }^{*}$ Geometric mean.

$B M I$, body mass index; $C H D$, coronary heart disease; $\mathrm{FEV}_{1}$, forced expiratory volume in one second; HDLC, high density lipoprotein cholesterol; LDLC, low density lipoprotein cholesterol.

during the estimated mid-trimester of intrauterine development was associated with reduced total height and specifically reduced leg length, but was not associated with reduced trunk length. Total height increased from $1.584 \mathrm{~m}(95 \%$ CI 1.581 to $1.588 \mathrm{~m})$ in the lowest quarter of mid-trimester temperature to $1.590 \mathrm{~m}(95 \%$ CI 1.586 to $1.594 \mathrm{~m})$ in the highest mid-trimester temperature quarter ( $\mathrm{p}$ trend $=0.07$ ). Similar results for leg length were $0.756 \mathrm{~m}(95 \%$ CI 0.753 to $0.759 \mathrm{~m})$ to $0.761 \mathrm{~m}(95 \% \mathrm{CI}$
0.758 to $0.764 \mathrm{~m}$ ) ( $\mathrm{p}$ trend $=0.01$ ). Temperature during the estimated mid-trimester was not associated with prevalent coronary heart disease or with any other coronary heart disease risk factors (all p values for trend $>0.2$ ). Temperature during the estimated last trimester of birth was associated with prevalent coronary heart disease, dyslipidaemia, and lung function, with similar patterns and magnitudes to those found for the association between temperature around the time of birth and these outcomes.
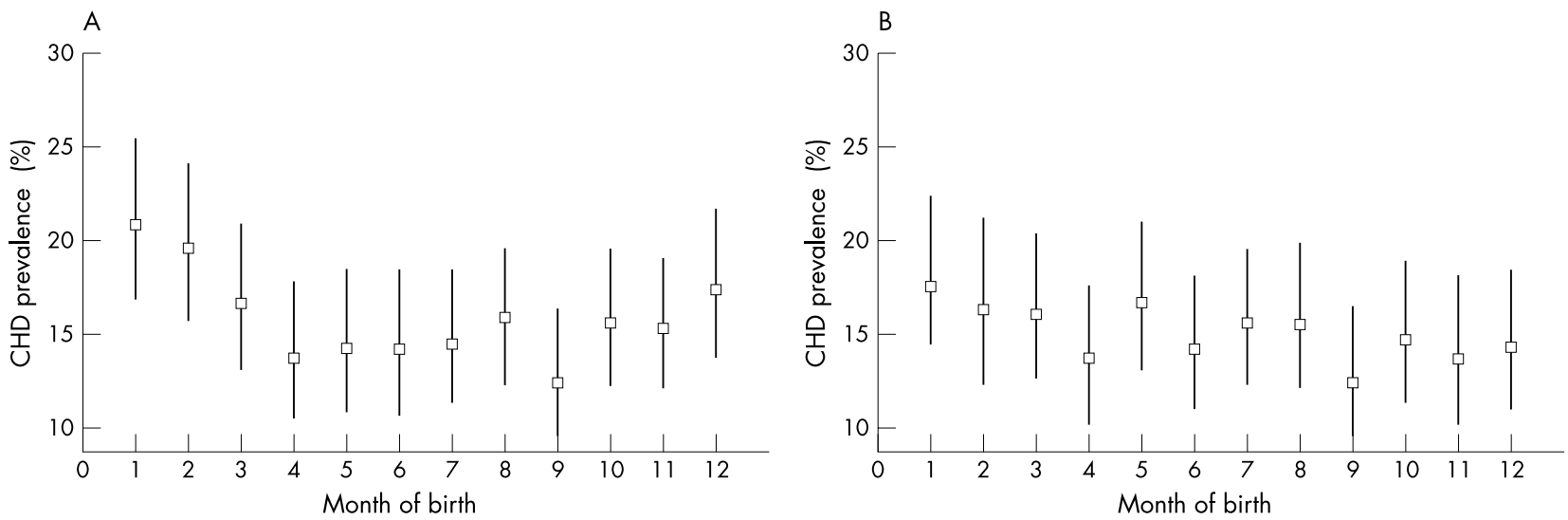

Figure 2 Age adjusted (A) and age plus temperature adjusted (B) coronary heart disease (CHD) prevalence by month of birth among British women aged 60-79 years. 
Table 3 Odds ratios of prevalent coronary heart disease comparing women in the lowest quarter of average temperatures of month of birth with those in the highest three quarters

\begin{tabular}{|c|c|c|c|}
\hline $\begin{array}{l}\text { Variables included } \\
\text { in model }\end{array}$ & $\begin{array}{l}\text { Number with complete } \\
\text { data on all variables } \\
\text { included in model }\end{array}$ & $\begin{array}{l}\text { Age adjusted } \\
\text { OR }(95 \% \mathrm{Cl})\end{array}$ & $\begin{array}{l}\text { Fully adjusted } \\
\text { OR }(95 \% \mathrm{CI})\end{array}$ \\
\hline Metabolic risk factors* & 3438 & 1.25 (1.01 to 1.53$)$ & $1.20(0.98$ to 1.46$)$ \\
\hline $\begin{array}{l}\text { Smoking and lung function } \\
\text { Adult anthropometric }\end{array}$ & 3724 & 1.24 (1.02 to 1.52$)$ & $1.18(0.98$ to 1.44 \\
\hline $\begin{array}{l}\text { measurest } \\
\text { Childhood and adult social }\end{array}$ & 3745 & 1.25 (1.03 to 1.52$)$ & $1.24(1.01$ to 1.51$)$ \\
\hline class and education & 4091 & $1.24(1.03$ to 1.50$)$ & 1.23 (1.03 to 1.50 \\
\hline Season of birth & 4091 & 1.24 (1.03 to 1.50$)$ & $1.24(1.03$ to 1.50$)$ \\
\hline Month of birth & 4091 & $1.24(1.03$ to 1.50$)$ & $1.21(1.01$ to 1.48 \\
\hline Latitude & 4091 & $1.24(1.03$ to 1.50$)$ & 1.19 (1.00 to 1.47$)$ \\
\hline $\begin{array}{l}\text { All explanatory and } \\
\text { confounding factorsł }\end{array}$ & 3347 & 1.25 (1.00 to 1.55$)$ & $1.19(0.95$ to 1.48$)$ \\
\hline
\end{tabular}

*Systolic blood pressure, diastolic blood pressure, low density lipoprotein cholesterol, high density lipoprotein cholesterol, triglyceride concentrations (logged), waist-hip ratio (all entered as continuous variables), insulin resistance diabetes categories (indicator variables: fifths of HOMA score and diabetes). †Body mass index, leg length, and trunk length (all entered as continuous variables). $\ddagger$ All variables included in the five previous models.

SFully adjusted $=$ adjusted for the variables listed in first column; in each case the age adjusted estimate is based only on those with complete data included in the final fully adjusted model.

$\mathrm{Cl}$, confidence interval; $\mathrm{OR}$, odds ratio.

\section{DISCUSSION}

Cold outdoor temperature around the time of birth is associated with increased coronary heart disease, insulin resistance, dyslipidaemia, and poor lung function. Women born during the winter have a greater prevalence of coronary heart disease than those born at any other time of year, but this increased risk is removed by adjustment for outdoor temperature around the time of birth, suggesting that temperature is the most important seasonal factor associated with increased heart disease risk. This is further supported by the finding that adjustment for latitude-which will reflect sunlight exposure and general deprivation in Britain as well as being associated with temperature-only slightly attenuated the association (table 3 ). The relation between cold temperature around the time of birth and coronary heart disease was most pronounced among those from the lowest socioeconomic class in childhood, suggesting an individual level effect of cold exposure that can be overcome with adequate protection. Though cold outdoor temperature around the time of birth is associated with low birth weight, the association between temperature at birth and coronary heart disease is independent of birth weight. No associations between temperature during first and second trimester and coronary heart disease were detected.

Two previous northern hemisphere studies have reported increased coronary heart disease and circulatory disease mortality during the spring months, ${ }^{2}{ }^{3}$ which is in contrast to our findings. In both of these studies the seasonal patterns were related to food availability, and associations with measures of outdoor temperature were not assessed. Our findings have some consistency with the theory that exposure to cold temperatures around the time of birth leads to increased fat storage and insulin resistance, and thence to coronary heart disease in later life, ${ }^{8-1013}$ though we did not find any strong associations between temperature around the time of birth and obesity. Further, the associations between cold outdoor temperature and insulin resistance and triglyceride concentrations were modest and may have been due to chance. However, these associations could also have been diluted by misclassification as each measurement was assessed at only one time point. Our finding of no association between temperature around the time of birth and obesity is consistent with a recent study of British women and men aged 59-73 years which showed an association between cold outdoor temperature at the time of birth and increased body mass index in men but not in women. ${ }^{13}$

\section{Study strengths and limitations}

The main strengths of our study are the detailed data on outdoor temperature at birth, extensive risk factor measures, and the association of this with coronary heart disease outcomes. Our response rate $(60 \%)$ is moderate but

Table 4 Odds ratio of prevalent coronary heart disease comparing women in the lowest quarter of average temperatures of month of birth with those in the highest three quarters of average temperatures of month of birth stratified by childhood socioeconomic position

\begin{tabular}{llll}
\hline $\begin{array}{l}\text { Childhood socioeconomic } \\
\text { class* }\end{array}$ & $\begin{array}{l}\text { Number with complete } \\
\text { data on all variables } \\
\text { included in final model }\end{array}$ & $\begin{array}{l}\text { Age adjusted } \\
\text { OR (95\% CI) }\end{array}$ & $\begin{array}{l}\text { Fully adjustedt } \\
\text { OR (95\% Cl) }\end{array}$ \\
\hline $\begin{array}{l}\text { Non-manual social class } \\
\begin{array}{l}\text { Manual social class } \\
\text { No occupational data for father }\end{array}\end{array}$ & 665 & $1.07(0.63$ to 1.76$)$ & $1.01(0.55$ to 1.74$)$ \\
$\begin{array}{l}\text { (most probably long term } \\
\text { unemployed) }\end{array}$ & 458 & $1.25(0.97$ to 1.54$)$ & 1.18 (0.89 to 1.51) \\
\hline
\end{tabular}

*Based on father's longest held occupation during participant's childhood.

†Systolic blood pressure, diastolic blood pressure, low density lipoprotein cholesterol, high density lipoprotein cholesterol, triglyceride levels (logged), forced expiratory volume (litre/s), waist-hip ratio, body mass index, leg length and trunk length, latitude (all entered as continuous variables), diabetes-insulin resistance categories (entered as continuous variables), smoking status (never, ex, current, entered as indicator variables), month of birth (entered as indicator variables). 
consistent with other baseline data in large epidemiological surveys, including the health survey for England in which participants were visited in their own homes. ${ }^{21}$ Responders were younger and less likely to have diabetes than nonresponders, though coronary heart disease prevalence was similar among responders and non-responders. The associations found in this study would only be exaggerated if the associations in non-responders were in the opposite direction to, or considerably weaker than, those in participants, which seems unlikely. Our study is cross sectional and a potential limitation is survivor bias. This would be important if large numbers of deaths from coronary heart disease occurred before the age of 60 years and if the exposure variables were associated with survival. Mortality from coronary heart disease among women before the age of 60 is uncommonfor example, in England and Wales in 1998 just 966 women between the age of 30-60 years died of coronary heart disease, giving a mortality of 0.53 per 100000 (data obtained from the Office for National Statistics electronic dataset (CD), "Twentieth century mortality: 95 years of mortality data in England and Wales by age, sex, year and underlying cause"). Survivor bias is therefore unlikely to explain our results. We used self report of birth weight and this was only available on one third of the sample. These data have, however, been shown to be associated with adult anthropometric measures, with the magnitudes and directions that would be expected on the basis of hospital recorded birth weight data. ${ }^{19}$

The association with outdoor temperature exposure complements earlier studies which did not assess temperature data but examined the association between season of birth and mortality and risk factor outcomes. However, we do not know whether those women born in colder months were in fact exposed to colder temperatures, as the subjects will have differed with respect to their access to a well heated home and warm clothing. However, the association between cold exposure around the time of birth and coronary heart disease prevalence was largely confined to persons belonging to manual occupational social classes in childhood or whose fathers were most probably unemployed; this suggests that cold exposure at an individual level may be important. The assumption here is that those who were in the lowest socioeconomic class as children will have been least likely to have been well protected by heating and clothing from outdoor cold exposures.

We do not have data on gestational age and therefore our estimate of the effects of mean outdoor temperatures around the times of intrauterine development-which assume all women were born at term-may be inaccurate. Over $90 \%$ of births in developed countries occur between 37-40 weeks' gestation and our estimates will have some discriminatory power between different stages of gestation. However, it is impossible with our data to determine whether the effect of temperature around the time of birth reflects a late intrauterine or an early postnatal effect.

\section{Implications}

Various early life environmental exposures, including intrauterine and postnatal growth, infant nutrition, and childhood socioeconomic class have been shown to be associated with insulin resistance and coronary heart disease in later life in women and men..$^{22}{ }^{23}$ The results of the current study suggest that exposure to cold in early life is a further risk factor for increased insulin resistance and coronary heart disease. The women assessed in this study were born between 1919 and 1940, a time of economic hardship in Britain. While there is no reason to suspect that cold exposure will have differing effects on children born in Britain or elsewhere in current times, it is possible that the extent of cold exposure differs. In a modern world, where it is relatively technically easy to keep a home and person warm, failure to do so tends to be related to housing quality and poverty. Waiting at the bus stop in the cold and not being able to heat the home adequately are markers of social and economic position. Current housing quality in Britain tends to be worse in areas of colder climate, ${ }^{24}$ and contemporary children born in cold climates who live in poor housing may be at increased risk of heart disease. It is impossible to change the climate in Britain, but it is possible to improve housing quality. These findings help to strengthen our emerging understanding of how inequality in socioeconomic characteristics can interact with a "natural" inequality in the physical environment to generate and exacerbate health inequalities. ${ }^{24}$ It was impossible in this study to determine whether the effect of cold exposure is most important during the third trimester of intrauterine development or during the very early postnatal period. Further research is required to determine which time period is most important.

\section{ACKNOWLEDGEMENTS}

The British women's heart and health study is co-directed by Professor Shah Ebrahim, Professor Peter Whincup, Dr Goya Wannamethee, and Dr Debbie Lawlor. We thank Carol Bedford, Alison Emerton, Nicola Frecknall, Karen Jones, Rita Patel, Mark Taylor, and Katherine Wornell for collecting and entering data, all of the general practitioners and their staff who have supported data collection, and the women who have participated in the study. The 0.5 1901-1995 monthly climate time-series data were supplied by the Climate Impacts LINK Project (UK Department of the Environment Contract EPGl/1/16) on behalf of the Climatic Research Unit, University of East Anglia. We thank Dr H Hemingway, University College London, who made useful comments on an earlier draft.

The British women's heart and health study is funded by the Department of Health. DAL was funded by a Medical Research Council/Department of Health (UK) research training fellowship and is now funded by a Department of Health career scientist award. RM is employed by the Research Unit in Health, Behaviour and Change (RUHBC). RUHBC is funded by the Chief Scientist Office of the Scottish Executive Health Department (SEHD) and the Health Education Board for Scotland (HEBS). The views expressed in this publication are those of the authors.

\section{Authors' affiliations}

D A Lawlor, G Davey Smith, S Ebrahim, Department of Social Medicine, University of Bristol, Bristol, UK

R Mitchell, Research Unit in Health, Behaviour and Change, University of Edinburgh, Edinburgh, UK

\section{REFERENCES}

1 Huntington E. Season of birth. Its relation to human abilities. New York: John Wiley and Sons, 1938.

2 Doblhammer G, Vaupel JW. Lifespan depends on month of birth. Proc Natl Acad Sci USA $2001 ; 98: 2934-9$.

3 Vaiserman AM, Collinson AC, Koshel NM, et al. Seasonal programming of adult longevity in Ukraine. Int J Biometeorol 2002;47:49-52.

4 Miura T, Shimura M. Longevity and season of birth. Jpn J Biometeorol 1980;17:27-31.

5 Gavrilov LA, Gavrilova NS. Season of birth and human longevity. J Antiaging Med 1999;2:365-6.

6 Doblhammer G. Longevity and month of birth: evidence from Austria and Denmark. Demogr Res 1999;1:1-22.

7 Moore SE, Halsall I, Howarth D, et al. Glucose, insulin and lipid metabolism in rural Gambians exposed to early malnutrition. Diabet Med 2001;18:646-53.

8 Newman MT. The application of ecological rules to the racial anthropology of the aboriginal new world. Am Anthropologist 1953;1 1:533-58.

9 Newman RW, Munro EH. The relation of climate and body size in US males. Am J Phys Anthropol 1955;13:1-15.

10 Young JB, Shimano Y. Effects of rearing temperature on body weight and abdominal fat in male and female rats. Am J Physiol 1998;274:R398-405.

11 Fitt $A B$. The heights and weights of men according to month of birth. Hum Biol 1955;27:138-42.

12 Hillman RW, Conway HC. Season of birth and relative body weight. Am J Clin Nutr 1972;25:279-81. 
13 Phillips DI, Young JB. Birth weight, climate at birth and the risk of obesity in adult life. Int J Obes Relat Metab Disord 2000;24:281-7.

14 Lawlor DA, Bedford C, Taylor M, et al. Geographic variation in cardiovascular disease, risk factors and their control in older women: British Women's Heart and Health Study. J Epidemiol Community Health 2003;57:134-40

15 New M, Hulme M, Jones P. Representing twentieth-century space-time climate variability. Part II: development of 1901-96 monthly grids of terrestrial surface climate. J Climate 2000;13:2217-38.

16 Burrough P, McDonnell R. Principles of geographic information systems. Oxford: Clarendon Press, 1998.

17 Waldie KE, Poulton R, Kirk IJ, et al. The effects of pre- and post-natal sunlight exposure on human growth: evidence from the Southern Hemisphere. Early Hum Dev 2000;60:35-42.

18 Moore SE, Cole TJ, Poskitt EM, et al. Season of birth predicts mortality in rural Gambia. Nature 1997;388:434.
19 Lawlor DA, Ebrahim S, Davey Smith G. The association between components of adult height and type II diabetes and insulin resistance: British women's heart and health study. Diabetologia 2002;45:1097-106.

20 Lawlor DA, Ebrahim S, Davey Smith G. Socioeconomic position in childhood and adulthood and insulin resistance: cross sectional survey using data from the British women's heart and health study. BMJ 2002;325:805-7.

21 Erens B, Primatesta P. Health survey for England 1998: cardiovascular disease. London: HMSO, 1999.

22 Leon D, Ben-Shlomo Y. Preadult influences on cardiovascular disease and cancer. In: Kuh D, Ben-Shlomo Y, eds. A life course approach to chronic disease epidemiology. Oxford: Oxford University Press, 1997:45-77.

23 Lawlor DA, Ebrahim S, Davey Smith G. A lifecourse approach to coronary heart disease and stroke. In: Kuh D, Hardy R, eds. A life course approach to women's health. Oxford: Oxford University Press, 2002:86-120.

24 Mitchell R, Blane D, Bartley M. Elevated risk of high blood pressure: climate and the inverse housing law. Int J Epidemiol 2002;31:831-8.

\section{IMAGES IN CARDIOLOGY}

\section{Caseous calcification of the mitral annulus: an underappreciated variant}

A

74 year old woman was found to have a calcified mass on a plain chest radiograph. Follow up studies identified a large, densely calcified mitral periannular mass, consistent with mitral annular calcification (MAC). Three months later, she presented with the acute onset of lethargy. Initial laboratory studies were remarkable only for an elevated serum calcium concentration of $14.8 \mathrm{mg} / \mathrm{dl}$ (normal range, $8.5-10.5 \mathrm{mg} / \mathrm{dl}$ ). She was treated with intravenous fluids and pamidronate and, over the following 48 hours, her neurologic status and serum calcium concentration returned to baseline with no residual sequelae.

Metabolic evaluation revealed parathyroid hormone values to be mildly reduced, with normal 1,25 dihydroxyvitamin D and serum phosphorous concentrations. No evidence of neoplasm could be identified upon computed tomography, bone scanning, and bronchoscopy. Repeat echocardiography revealed a more heterogeneous appearance of the mitral periannular mass with a clear, central echolucent zone (panels below, Ao, aorta; LA, left atrium). Whether the

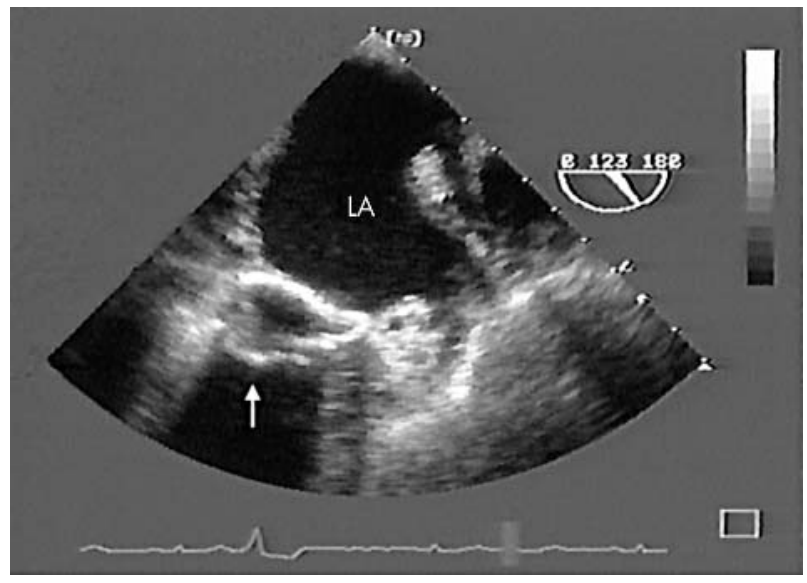

hypercalcaemic state and mitral annular changes were directly or causally related to the caseous transformation of MAC is unclear.

Caseous calcification of the mitral annulus is a relatively rare variant with an echocardiographic prevalence of $0.6 \%$ in patients with MAC and $0.06-0.07 \%$ in large series of patients of all ages. Caseous calcification is defined echocardiographically as a large, round or semilunar, echodense mass in the periannular mitral region, which contains central areas of echolucencies resembling liquefaction. As the prevalence of caseous calcification in echocardiographic studies is less than that of necropsy series, it is likely that the widespread use and improvements in echocardiography may increasingly uncover this condition, which has been greatly underappreciated and, at times, unrecognised.

G M Novaro, B P Griffin, D F Hammer novarog@ccf.org

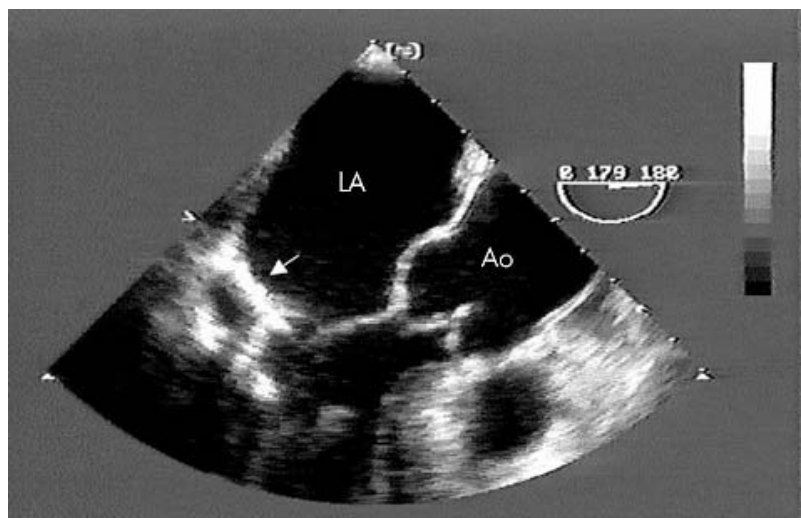

